DEPARTMENT OF ECONOMICS

UNIVERSITY OF CYPRUS

EU ENLARGEMENT: ARE THE NEW COUNTRIES READY TO JOIN THE EMU?

Minoas Koukouritakis and Leo Michelis

Discussion Paper 2003-06

P.O. Box 20537, 1678 Nicosia, CYPRUS Tel.: ++357-2-892430, Fax: ++357-2-892432

Web site: http://www.econ.ucy.ac.cy 


\title{
EU Enlargement: Are the New Countries Ready to Join the EMU?
}

\author{
Minoas I. Koukouritakis \\ Department of Economics \\ University of Cyprus \\ Nicosia, CY 1678 \\ Cyprus \\ minos@ucy.ac.cy
}

\author{
Leo Michelis \\ Department of Economics \\ Ryerson University \\ Toronto, ON \\ Canada, M5B 2K3 \\ michelis@ryerson.ca
}

August 2003

\begin{abstract}
This paper investigates empirically the extend to which the ten new countries of the current EU enlargement are ready to join the European Monetary Union (EMU). We assess the prospects of successful accession into the EMU using cointegration and common trends analysis on the nominal convergence criteria specified by the Maastricht Treaty as well as on real per capita GDPs. The empirical results indicate that the enlargement countries are partially ready to join the Eurozone, and need further adjustments in their government policies to be fully prepared for joining the EMU.
\end{abstract}

JEL Classification: F15, F33, F42

Keywords: Economic Integration, EU Enlargement, Cointegration, Common Trends

The second author would like to thank the Social Sciences and Humanities Research Council of Canada for financial support. All the remaining errors are our own. 


\section{Introduction}

The enlargement process of an economic or monetary union is an important issue in the theory and practice of economic integration. In the context of the European Union (EU), enlargement has been a concern ever since its inception as European Economic Community by the Treaty of Rome in 1957. The Treaty states explicitly that one of its main objectives was continuous and balanced expansion; see for example Pelkmans 2001, pp. 31-32. Indeed the current EU is the result of various rounds of expansions since the Treaty of Rome.

After growing in size from the original six members to twelve members and presently to fifteen member states, the EU is currently preparing for the biggest expansion ever in terms of scope and diversity. Of the thirteen countries that have applied to become members, ten countries are set to join the Union on May 1, 2004. These countries are Cyprus, the Czech Republic, Estonia, Hungary, Latvia, Lithuania, Malta, Poland, the Slovak Republic and Slovenia ${ }^{1}$. In order to join the EU these prospective member countries must satisfy certain economic and political criteria which include being stable democracies, respect human rights and the rule of law as well as having a functioning market economy.

Assuming that all ten countries successfully join the EU by May 2004, another important question is the extend to which they can be ready to join the European Monetary Union (EMU), and thus increase the current size of the Eurozone. The more ready they are the less the costs of adjusting their fiscal and monetary policies relative to the Union's, the faster they will adopt the euro and the greater the benefits and influence of the EU in the international economy.

In the present paper we assess the prospects of the 10 new countries joining the EMU based on the nominal convergence criteria laid down by the Maastricht Treaty for a country's successful participation in the monetary union. Specifically, in order to qualify for joining the EMU a country:

(a) must not devalue its currency within 2 years preceding entry into the monetary union;

(b) must have an inflation rate not higher than 1.5 per cent above the average of the three countries with the lowest inflation rates

(c) must have a long term interest rate not higher than 2 percentage points above the average of the three countries with the lowest inflation rates; and

(d) must have government deficits and debts not exceeding 3 per cent and 60 per cent of GDP respectively.

Clearly the conditions (a) to (d) impose constraints on the behavior of

\footnotetext{
${ }^{1}$ The other three countries are Bulgaria, Romania that hope to join by 2007, and Turkey that is not currently negotiating for membership.
} 
the exchange rates, interest rates, deficits and debts of the prospective member countries. For instance even if individual interest rates may fluctuate and be nonstationary over time, the interest rates of all the countries should not deviate beyond two percentage points above the average of the three countries in the union with the lowest inflation rates. Similar arguments apply for the other variables in the nominal convergence criteria.

The statistical notion of cointegration is well suited to study the comovements of a set of variables in the long run. By definition, a set of possibly nonstationary variables are cointegrating if there exists linear combinations or cointegrating relations among them that are stationary and move together over time. The cointegrating relations have the appealing economic interpretation of long run equilibrium relationships among the variables under study. In general if there exist $r$ cointegrating relations in a set of $p$ variables, there must also exist $p-r$ common stochastic trends that move these variables around their equilibrium paths, and thus "drive" the cointegrating relations.

The empirical literature relating to different aspects of the nominal convergence criteria in the EU has been quite large. Among others, Karfakis and Moschos (1990) used the bivariate framework of Engle and Granger (1987) to investigate interest rate linkages between Germany and each of the countries, Belgium, France, Ireland, Italy and the Netherlands. Using monthly data from 1979:4 to 1988:11, they found no evidence of cointegration in the pairs of interest rates. MacDonald and Taylor (1991) used monthly data from 1979:3 to 1988:12 to analyze bilateral US dollar nominal and real exchange rates for three EMS countries (France, Germany and Italy) and three non-EMS countries (Canada, Japan and Britain). Based on Johansen's multivariate cointegration method, these authors found some evidence of cointegration in the two types of exchange rates. Similarly, Hafer and Kutan (1994) adopted the multivariate cointegration framework to test for long run co-movements of short term interest rates and money supplies in a group of five EMS countries. Using monthly data from 1979:3 to 1990:12, they reported evidence of partial policy convergence among these countries. Bayoumi and Taylor (1995) compared the behavior of real output growth and inflation of countries participating in the Exchange Rate Mechanism (ERM) with a group of non-ERM countries. They concluded that the ERM had contributed to macro-policy coordination among the ERM members. Haug, MacKinnon and Michelis (2000) employed Johansen's cointegration approach to determine which EU countries would form a successful monetary union based on the Maastricht nominal convergence criteria. Using monthly and quarterly data of various time spans from 1979 to 1995 on 12 EU countries, these authors suggested that not all of the 12 countries would form a successful monetary union over time, unless several countries make significant adjustments in their fiscal and monetary policies.

Even though most theoretical and empirical studies to date have been 
concerned with estimating and analyzing cointegrating relations, common trends analysis can be equally useful and insightful. The identification and estimation of common trends in a set of economic variables can convey information that may be important and useful to applied economists and policy makers. Consider for instance the long term interest rates of France, Germany and the Netherlands. If one finds two cointegrating relations among the three interest rates, then there must be a common stochastic trend shared among them. Identifying which country or combination of countries determines the common trend can be very useful information to policy makers for the design of their monetary policies. Hafer, Kutan and Zhou (1997) used the multivariate cointegration and common trends techniques of Gonzalo and Granger (1995) to study linkages in the term structures of interest rates in 4 EMS countries: Belgium, France, Germany and the Netherlands. Using a sample of monthly observations from 1979:3 to 1995:6 and decomposing each term structure into its transitory and common trend components, these authors found that the long term interest rate, and not the short rate, is the source of the common trend in each country. Further, the common trends are cointegrated and thus move together over time, but no single country dominates the common trends in the long term interest rates of the four EMS countries.

In the present paper we contribute to the existing literature in several ways. First, we use the most recent data available from the early 1990s to the present and the multivariate cointegration approach of Johansen (1988, $1994,1995)$ to analyze the cointegrating relations among the exchange rates, inflation rates, interest rates, deficits and debts of the 10 new prospective EU members mentioned above, and subsets of them in relation to the 3 EMU countries, France, Germany and the Netherlands. Evidence of cointegration in each set of variables among the 10 new countries or in combination with the 3 EMU countries would imply that these variables tend to move together in the long run, and that deviations from the long run relationships will be stationary. Unless the key variables of the nominal convergence criteria are tied together this way, the prospects of the new countries joining the EMU successfully would be indeed slim.

Second, in addition to the nominal convergence criteria, we also analyze the long run cointegration properties of real per capita GDPs among the 10 new countries and the 3 EMU countries. We view evidence of long run comovements in real per capita GDPs as strengthening the case for successful EMU enlargement by some or all the new countries.

Third, we use the Gonzalo and Granger methodology to identify and estimate the number common trends that drive the cointegrating relations in each group of variables. Hypothesis testing on the estimated vectors that enter the common trends provides information as to which countries contribute significantly to the common trends. This is useful information for the adjustment and design of government policies of the prospective EMU 
countries.

The rest of the paper is as follows. In Section 2 we outline the models for cointegration and common trends that we use in the paper. In Section 3 we describe the data and we present and analyze the empirical results on cointegration and common trends. Briefly, the evidence suggests that there is partial co-movement of the nominal and real variables among the 10 new countries and the 3 EMU countries, suggesting that adjustment of policies of the new countries would be desirable to successfully join the EMU. In Section 4 we make some concluding remarks.

\section{The Cointegration and Common Trends Models}

In this section we outline the basic maximum likelihood theory and the models that we employ in the subsequent empirical analysis. The maximum likelihood theory of multivariate cointegration assumes that the stochastic variables are integrated of order one, or $I(1)$, and that the data generating process is a Gaussian vector autoregressive model of finite order $k$, or $V A R(k)$ which may possibly include some deterministic components. Let $Y_{t}$ be a $p$-dimensional column vector of $I(1)$ variables. Then the $V A R(k)$ can be written in a vector error-correction model (VECM) form as

$$
\Delta Y_{t}=\Pi Y_{t-1}+\sum_{i=1}^{k-1} \Gamma_{i} \Delta Y_{t-i}+\mu_{0}+\mu_{1} t+\epsilon_{t}, \quad t=1 \ldots T
$$

where $\Pi$ and $\Gamma_{i}$ are $p \times p$ matrices of coefficients, $\mu_{0}$ and $\mu_{1}$ are $p \times 1$ vectors of constant and trend coefficients, respectively and $\epsilon_{t}$ is a $p \times 1$ multivariate normal random error vector with mean vector zero and covariance matrix $\Omega$ that is independent across time periods.

The hypothesis of cointegration can be stated in terms of the long run matrix $\Pi$ in (1). This matrix can always be written as

$$
\Pi=\alpha \beta^{\prime}
$$

where $\alpha$ and $\beta$ are $p \times r$ matrices of full rank. If $r=0$, then $\Pi=0$, which means that there is no linear combination of the elements of $Y_{t}$ that is stationary. The other extreme case is when the rank of the $\Pi$ matrix equals $p$. In this case $Y_{t}$ is a stationary process. In the intermediate case, when $0<r<p$ we have $r$ stationary linear combinations of the elements of $Y_{t}$ and $p-r$ common trends.

Under the hypothesis $\Pi=\alpha \beta^{\prime}$, the relation between $\alpha$ and the deterministic term $\mu_{t} \equiv \mu_{0}+\mu_{1} t$ is crucial for the properties of the process $Y_{t}$. To see this, first we decompose $\mu_{0}$ and $\mu_{1}$ in the directions of $\alpha$ and $\alpha_{\perp}$, where $\alpha_{\perp}$ is a $p \times(p-r)$ matrix that is orthogonal to $\alpha$ : 


$$
\mu_{i}=\alpha \beta_{i}+\alpha_{\perp} \gamma_{i}, \quad i=0,1
$$

where $\beta_{i}=\left(\alpha^{\prime} \alpha\right)^{-1}$ and $\gamma_{i}=\left(\alpha_{\perp}^{\prime} \alpha_{\perp}\right)^{-1} \alpha_{\perp}^{\prime} \mu_{i}$. Next, following Johansen (1995), we consider the following five submodels, which are ordered from the most to the least restrictive:

Model 0: $\mu_{t}=0$

Model $1 *: \mu_{t}=\alpha \beta_{0}$

Model 1: $\mu_{t}=\alpha \beta_{0}+\alpha_{\perp} \gamma_{0}$

Model $2^{*}: \mu_{t}=\alpha \beta_{0}+\alpha_{\perp} \gamma_{0}+\alpha \beta_{1} t$

Model 2: $\mu_{t}=\alpha \beta_{0}+\alpha_{\perp} \gamma_{0}+\left(\alpha \beta_{1}+\alpha_{\perp} \gamma_{1}\right) t$

The interpretation of these models becomes clear in the context of the solution of $Y_{t}$ in equation (1) using a version of the Granger Representation Theorem (see Johansen, 1991, Theorem 4.1). The solution is given by

$$
Y_{t}=C \sum_{i=1}^{t} \epsilon_{t}+\frac{1}{2} \tau_{2} t^{2}+\tau_{1} t+\tau_{0}+W_{t}+A
$$

where $W_{t}$ is a stationary process, $A$ is a vector such that $\beta^{\prime} A=0, C=$ $\beta_{\perp}\left(\alpha_{\perp}^{\prime} \Gamma \beta_{\perp}\right)^{-1} \alpha_{\perp}^{\prime}, \Gamma=I_{p}-\sum_{i=1}^{k-1} \Gamma_{i}, \beta_{\perp}$ is a $p \times(p-r)$ matrix of full rank that is orthogonal to $\beta$ and $\tau_{2}=C \mu_{1}$.

The five submodels imply different behavior for the process $Y_{t}$ and the cointegrating relations $\beta^{\prime} Y_{t}$. In Model $0, Y_{t}$ has no deterministic trend and all the stationary components have zero mean. In Model $1^{*}, \mu_{1}=0$ implying $\tau_{2}=C \mu_{1}=0$. From (4), this means that $Y_{t}$ has no quadratic trend. We also have that $\alpha_{\perp}^{\prime} \mu_{0}=0$ implying $\tau_{1}=C \mu_{0}=0$. Therefore, $Y_{t}$ has no linear trend. However, both $Y_{t}$ and the cointegrating relations $\beta^{\prime} Y_{t}$ are allowed a constant term. In Model $1, \alpha_{\perp}^{\prime} \mu_{0} \neq 0$ so that $\tau_{1} \neq 0$. Therefore, $Y_{t}$ has a linear trend. However, since $\beta^{\prime} \tau_{1}=\beta^{\prime} C \mu_{0}=0$, the cointegrating relations $\beta^{\prime} Y_{t}$ have no linear trend. In Model $2^{*}, Y_{t}$ has no quadratic trend as $\alpha_{\perp}^{\prime} \mu_{1}=0$ which implies $\tau_{2}=C \mu_{1}=0$, but $Y_{t}$ has a linear trend that is present even in the cointegrating relations. In Model $2, \mu_{1} \neq 0$ implying $\tau_{2}=C \mu_{1} \neq 0$, which allows for a quadratic trend in the process $Y_{t}$. In this case, the cointegrating relations $\beta^{\prime} Y_{t}$ have only a linear trend, as $\beta^{\prime} \tau_{2}=$ $\beta^{\prime} C \mu_{1}=0$.

Because of the normality assumption, we can test for the reduced rank of the $\Pi$ matrix using a likelihood ratio test. This procedure uses the technique of reduced rank regression, (e.g., see Johansen (1994)), and gives at once the maximum likelihood estimators (MLE) of $\alpha$ and $\beta$ and the eigenvalues needed in order to construct the likelihood ratio test. The MLE of $\alpha$ and $\beta$ are obtained by regressing $\Delta Y_{t}$ and $Y_{t-1}$ on $\Delta Y_{t-1} \ldots \Delta Y_{t-k}$ and $\mu_{t}$ (allowing for the restrictions imposed by each of the five models). These reduced rank regressions give residuals $R_{0 t}$ and $R_{i t}$ respectively, and residual product matrices 


$$
S_{i j}=T^{-1} \sum_{t=1}^{T} R_{i t} R_{j t}^{\prime}, \quad i, j=0,1
$$

Solving the eigenvalue problem

$$
\left|\lambda S_{11}-S_{10} S_{00}^{-1} S_{01}\right|=0
$$

for eigenvalues $1>\hat{\lambda}_{1}>\ldots>\hat{\lambda}_{p}>0$ and eigenvectors $\hat{V}=\left(\hat{v}_{1} \ldots \hat{v}_{p}\right)$, normalized such that $\hat{V}^{\prime} S_{11} \stackrel{\wedge}{V}=I$, we get the MLE of $\alpha$ and $\beta$ as $\stackrel{\wedge}{\alpha}=S_{01}$ $\hat{\beta}$ and $\hat{\beta}=\left(\hat{v}_{1} \ldots \hat{v}_{r}\right)$, where $\left(\hat{v}_{1} \ldots \hat{v}_{r}\right)$ are the eigenvectors associated with the $r$ largest eigenvalues of $(6)$.

In testing the null hypothesis that $\operatorname{rank}(\Pi) \leq r$ against the alternative hypothesis is that $\operatorname{rank}(\Pi)=p$, the likelihood ratio statistic, called also the Trace statistic by Johansen and Juselius (1990), is given by

$$
\text { Trace }=-T \sum_{i=r+1}^{p} \ln \left(1-\hat{\lambda}_{i}\right)
$$

The testing is performed sequentially for $r=0, \ldots, p-1$ and it terminates when the null hypothesis is not rejected for the first time.

The asymptotic distribution of the test statistic in equation (7) is nonstandard and depends only on $(p-r)$. In the literature, asymptotic critical values for the Trace statistic in equation (7) have been calculated by Monte Carlo simulations of a $(p-r)$-dimensional discrete random walk with 400 steps; see for example Osterwald-Lenum (1992) and Johansen (1995). However, MacKinnon et al. (1999) have shown that this approach leads to quite inaccurate critical values, especially when $(p-r)$ is large. They also have computed much more accurate critical values for the Trace statistic in (7) using the response surface methodology. Since we deal with large dimensional systems in this study, we use these new critical values for testing hypotheses.

In respect to common trends, it is clear from equation (4) that the common trends in $Y_{t}$ are contained in the first term of that expression. Given the definition of $C$, Johansen (1995, p. 41) defines the common trends by the cumulated disturbances $\alpha_{\perp}^{\prime} \sum_{i=1}^{t} \epsilon_{t}$. Assuming that the common trends are a linear combination of $Y_{t}$, in the form $f_{t}=\alpha_{\perp}^{\prime} Y_{t}$, Gonzalo and Granger (1995) derive the MLE of $\alpha_{\perp}$ as the eigenvectors corresponding to the $(p-r)$ smallest eigenvalues of the problem

$$
\left|\lambda S_{00}-S_{01} S_{11}^{-1} S_{10}\right|=0
$$

Solving equation (8) for eigenvalues $1>\hat{\lambda}_{1}>\ldots>\hat{\lambda}_{p}>0$ and eigenvectors $\hat{M}=\left(\hat{m}_{1} \ldots \hat{m}_{p}\right)$,normalized such that $\hat{M}^{\prime} S_{00} \hat{M}=I$, we get the MLE of $\alpha_{\perp}$ 
as $\hat{\alpha}_{\perp}=\left(\hat{m}_{r+1} \ldots \hat{m}_{p}\right)$. The asymptotic distribution of $\hat{\alpha}_{\perp}$ is normal and it is straightforward to test hypotheses on $\alpha_{\perp}$ of the form,

$$
H_{0}: \alpha_{\perp}=G \theta
$$

where $\mathrm{G}$ is a $p \times m$ known matrix of constants and $\theta$ is an $(p-r) \times m$ matrix of unknown coefficients such that $p-r \leq m \leq p$. To carry out the test, one solves the eigenvalue problem

$$
\left|\lambda G^{\prime} S_{00} G-G^{\prime} S_{01} S_{11}^{-1} S_{10} G\right|=0
$$

for eigenvalues $1>\hat{\lambda}_{1}^{*}>\ldots>\hat{\lambda}_{p}^{*}>0$, and forms the likelihood ratio test statistic given by

$$
L=-T \sum_{i=r+1}^{p} \ln \left[\left(1-\hat{\lambda}^{*}{ }_{i+(m-p)}\right) /\left(1-\hat{\lambda}_{i}\right)\right]
$$

Under the null hypothesis $H_{0}: \alpha_{\perp}=G \theta$, the $L$-statistic in (10) is distributed as $\chi_{(p-r) \times(p-m)}^{2}$ asymptotically. In the next section, we make specific choices for the matrix $G$ and use the $L$-statistic in (10) to test various hypotheses of interest.

Gonzalo and Granger have derived their results under the assumption that the VECM has no deterministic components, that is they assumed that $\mu_{t}=0$. In the present study, our model selection tests indicated that this is a restrictive assumption and that models other than Model 0 describe best some variables in our data set. For this reason, we have included deterministic components in the VECM in (1). Extending the VECM by the inclusion of deterministic components does not invalidate the asymptotic distributions of $\hat{\alpha}_{\perp}$ and the $L$-statistic in (10). This follows from the fact that in computing these statistics, we have accounted appropriately in the reduced rank regressions for the restrictions imposed on $\mu_{t}$ by each of the models 0 to 2 above.

\section{Data and empirical results}

\subsection{Data}

Most of the data for the present study were obtained from the CD-ROM of the International Financial Statistics (IFS) of the IMF, 2003, and from the CD-ROM of the Statistical Compendium of the OECD, 2002. Other sources needed to complete the data set will be indicated below. We collected data for the 10 countries of the enlargement and for Germany, France and the Netherlands, the 3 EMU countries. The sample is comprised of monthly or quarterly data of varying time spans determined by data availability. The 
starting date for the data was January 1993, when the Czech and the Slovak Republic became independent states following the split of Czechoslovakia.

All exchange rates, interest rates and the real per capita GDP are expressed in natural logarithms. Monthly end-of period nominal euro exchange rates were constructed using monthly end-of period nominal US dollar exchange rates for the countries considered (line ae or ag of the IFS), and monthly end-of-period nominal exchange rates between euro and the dollar (line ae in the Euro Area section of the IFS). Monthly real euro exchange rates were constructed from monthly nominal euro rates and monthly CPI figures (line 64 in the IFS). The time span for nominal exchange rates, real exchange rates and inflation is 1993:1 to 2002:12. Monthly average longterm government bond yields for the Czech Republic, the Slovak Republic and the 3 EMU countries were obtained from line 61 of the IFS. For the three Baltic states, Latvia, Estonia and Lithuania, the long-term interest rates were taken from the CD-ROM of the Statistical Compendium of the OECD, which reports end-of-month figures instead of monthly averages. For Poland, the long-term government yields were taken from the Polish Ministry of Finance, while for Hungary, Slovenia, Malta and Cyprus the long term interest rates were taken from their respective Central Banks. Due to lack of data availability, the time span for long term interest rates is 1998:1 to $2002: 12$.

Complete quarterly government deficit or surplus data are available only for Cyprus, the Czech Republic, the Slovak Republic and the 3 EMU countries, and were obtained from line 80 of the IFS. The period covered for this variable is from 1993:1 to 2001:4. For Slovak Republic, the IFS data did not extend back to 1993:1 and we completed the series using data from the Central Bank of that country. To construct the deficit/GDP ratio, we used quarterly GDP from the line 99b of the IFS, except for Cyprus. Quarterly GDP data for Cyprus were obtained from the Central Bank of Cyprus. Quarterly data for general government debt are not available for any country and for this reason we used figures for central government debt instead. Central government debt data are available only for Cyprus, the Czech Republic, Poland and the 3 EMU countries. For the three enlargement countries government debt data were taken from line 88 of the IFS, while for the three EMU countries they were obtained from line $88 \mathrm{z}$ of the IFS. To construct the debt/GDP ratio we followed the same procedure as we did to construct the deficit/GDP ratio. The period covered for the debt/GDP ratio data is 1996:1 to 2001:4.

Complete data for real per capita GDP are available for all the enlargement countries and the 3 EMU countries. However, the data spans for Hungary, Malta and Poland were very small, and for this reason we dropped these countries from the sample on real per capita GDP. When available, real GDP data for the remaining ten countries were obtained from line 99bp or 99br of the IFS (GDP volume in 1995 prices), except for Estonia and 
Cyprus. For Estonia, data in either line in 1995 prices were not available, and we deflated nominal GDP (line 99b) with its 1995 base year deflator (line 99bip of the IFS). For Cyprus, real GDP was obtained by dividing nominal GDP with the CPI (line 64 of the IFS). Finally, real GDP for each country was converted to real per capita GDP by dividing it with the population figure for each country. these series were divided by the population of each country (line $99 \mathrm{z}$ of the IFS). The sample span for this variable is from 1993:1 to 2002:3.

\subsection{Cointegration models}

For the interpretation of the empirical results, we claim that there is "complete" convergence of government policies in a group of $p$ countries, if we find that there exist $r=p-1$ cointegrating vectors and a single shared common stochastic trend in a set of policy variables such as inflation rates. On the other hand, if $0<r<p-1$, then there is only "partial" convergence among the policies of the countries concerned; see Hafer and Kutan (1994). In this sense, convergence means that the countries' polices are aligned enough, so that the relevant variables move towards a long run equilibrium and do not drift too far apart over time. For example, if there exist two or more common stochastic trends among the interest rates or exchange rates of the 10 enlargement countries, then some of these countries set their policies independently in the long run. Consequently, there is only partial convergence of policies and some further adjustment in the policies of some countries may be required to successfully join the EMU.

Before testing for cointegration, we tested all time series for unit roots using the Augmented Dickey-Fuller test at the 5\% level of significance. The results are presented in Table 1. In order to select the appropriate lag length, we used the Akaike's information criterion. As shown in Table 1, we failed to reject the unit root hypothesis for most of the series. In the case of nominal exchange rates, the unit root hypothesis is rejected only for Latvia, Lithuania and Slovenia. ${ }^{2}$ In the case of CPI-inflation, the unit root hypothesis is rejected for Poland, the Slovak Republic, Slovenia, the three Baltic states and Germany. In the case of real exchange rates, the unit root hypothesis is rejected only for the three Baltic states, while in the case of interest rates, it is not rejected for any country. The unit root hypothesis is not rejected for any country in the cases of deficit/GDP and debt/GDP ratios, while in the case of real per capita GDP is rejected only for the Czech Republic. Based on these results we proceeded with cointegration analysis of the relevant sets of variables.

Tables 2, 3 and 4 report the Trace statistics and the critical values for nominal exchange rates, real exchange rates, inflation, interest rates,

\footnotetext{
${ }^{2}$ We did not test for a unit root the nominal exchange rates of the 3 EMU countries, as these countries have adopted a common currency since January 1, 1999.
} 
deficit/GDP ratio, debt/GDP ratio and real per capita GDP. Table 2 refers to the group of the 10 enlargement countries, while Table 3 combines the 10 enlargement countries with the 3 countries of the Eurozone. Because we do not have critical values for systems where $p \geq 13$, we left the Netherlands out of the analysis in the case of interest rates. We also used a subset of the enlargement countries that we call the enlargement core, which consists of the 5 countries with the higher real per capita GDP, namely Cyprus, Slovenia, Malta, the Czech Republic and Hungary. Table 4 reports the empirical results for the combined systems of the enlargement core and the 3 EMU countries.

To select the appropriate lag length, $k$, in equation (1), we set up a separate VECM for each set of these variables and used the likelihood ratio test to carry out hypothesis testing Under the hypothesis $\Gamma_{k}=0$, the likelihood ratio test is asymptotically distributed as $\chi^{2}$ with $p^{2}$ degrees of freedom; see Johansen, 1995, p. 21. Further, to determine which submodel describes best each set of variables, we tested the various submodels against each other using likelihood ratio tests in Johansen (1995), which are also distributed as $\chi^{2}$ with appropriate degrees of freedom. The degrees of freedom for testing pairs of the five nested submodels, which are nested from the most to the least restrictive, are defined as follows:

$$
0 \underset{r}{\subset} 1^{*} \underset{p-r}{\subset} 1 \underset{r}{\subset} 2^{*} \underset{p-r}{\subset} 2
$$

As shown in Table 2, we test of cointegration in nominal exchange rates for seven countries, as the nominal exchange rates of Latvia, Lithuania and Slovenia were found to be integrated of order zero. Using the Trace statistic at a $5 \%$ level of significance, we find two cointegrating vectors and five common trends among the seven nominal exchange rates. Similarly, in the case of real exchange rates, we excluded the three Baltic states that had stationary real exchange rates. In this case based on the Trace statistic, we find one cointegrating vector and six common stochastic trends. In the case of interest rates, we consider a 10-dimensional system and find eight cointegrating vectors and two common trends. For the deficit/GDP and debt/GDP ratios, we use two 5-dimensional systems for the five countries for which data is available. For the deficit/GDP ratio the Trace test detects one cointegrating vector and four common trends, while for the debt/GDP ratio the same test detects three cointegrating vectors and two common trends. In respect of inflation, only Cyprus, Malta, Hungary and the Czech Republic have $I(1)$ inflation rates. In this case, the Trace test finds three cointegrating vectors and one common trend at the 5 percent level of significance.

From the above results, it is clear that only in the cases of debt/GDP ratio and interest rates, the enlargement countries approach near full convergence, since we find two common trends and eight cointegrating vectors. Full convergence is also indicated in the case of inflation, but only among the 
four countries considered. In all other cases, we can say that there is only partial convergence of policies among the ten new EU enlargement countries. Clearly, some further adjustment of policies is necessary to better prepare some of the countries to join the EMU.

In the fifth column of the first panel of Table 2 we analyze the hypothesis of real convergence in terms of co-movements among the real per capita GDPs of the enlargement countries. Considering a 6-dimensional system (real per capita GDP is $I(0)$ for the Czech Republic, while we have no sufficient data for Hungary, Malta and Poland), we find two cointegrating vectors and four common trends among the six real per capita GDPs of Cyprus, the three Baltic states, Slovenia and the Slovak Republic. We interpret this result as evidence of partial real convergence among these countries.

Table 3 shows the empirical results for the combined system of the 10 new countries and the 3 EMU countries. For real exchange rates, we estimate a 10-dimensional system (excluding the three Baltic states with $I(0)$ real exchange rates from the 10 enlargement countries and adding the 3 EMU countries). Based on the Trace test we find two cointegrating relations and eight common trends at the 5 percent level. For the 6 -dimensional system of inflation rates, the Trace test indicates four cointegrating vectors and two common trends. In this system we include Cyprus, the Czech Republic, Malta, Hungary, France and the Netherlands. For the deficit/GDP ratio, we excluded Latvia and Poland due to small sample size, and estimated a 6-dimensional system consisting of Cyprus, the Czech Republic, the Slovak Republic and the 3 EMU countries. In this case, the Trace test indicates two cointegrating vectors and four common trends. For the analysis of the debt/GDP ratio, we excluded Hungary and Lithuania due to small sample size, and estimated a 6-dimensional system consisting of Cyprus, the Czech Republic, Poland and the 3 EMU countries. In this case we find three cointegrating vectors and three common trends. In the case of interest rates, we constructed and estimated a 12-dimensioned system consisting of the ten new countries, Germany and France. Here, the Trace test indicates ten cointegrating relations and two common trends. Finally, in the case of real per capita GDP, we estimated a 9-dimensioned system, consisting of the six new countries for which data is available (Cyprus, the three Baltic states, Slovenia and the Slovak Republic) and the 3 countries of the Eurozone. In this case, we find four cointegrating vectors and five common trends. Based on these results, we conclude that there is only partial nominal and real convergence between the ten new countries and the countries that are 3 members of the Eurozone.

In Table 4 we combine the five core enlargement countries with the 3 EMU countries. The empirical results are similar to those in Table 3. In cases of real exchange rates and interest rates, we estimate two 8-dimensional systems. In the former case the Trace test indicates two cointegrating vectors and six common trends, while in the latter case we find six cointegrating 
vectors and two common trends. In the cases of the deficit/GDP ratio and debt/GDP ratio, we estimated two 5-dimensional VECM's, consisting of Cyprus, the Czech Republic and the 3 countries of the Eurozone. In the former case we find three cointegrating vectors and two common trends, while in the latter case the Trace test indicates two cointegration relations and three common trends. These results show that there is only partial nominal convergence between the core enlargement countries and the 3 EMU countries.

On the real side, we find almost full convergence of real per capita GDPs between the enlargement countries with high income and the Eurozone countries. Based on the 5-dimensional VECM consisting of Cyprus, Slovenia and the 3 EMU countries, the Trace test indicates three cointegrating vectors and two common trends. This means that there is almost a co-movement of these countries' real outputs in the long run.

In summary, we can state that these results are mixed for the 10 enlargement countries, aspiring to join the EMU. Nonetheless, these results show the need for reform and coordination in government policies among the new enlargement countries and the EU countries, in order to achieve greater convergence of the key nominal and real variables that can sustain a common currency. These countries are close to moving together in the cases of inflation and long-term interest rates. But a lot of work has to be done, especially in fiscal policies to achieve convergence in fiscal criteria of deficit/GDP ratios and debt/GDP ratios. For example, tax and expenditure harmonization across the new countries, along with monetary adjustment, will increase the prospects for successful EMU accession, by increasing the number of cointegrating relations and thus, reducing the number of common trends. These reforms will also help these countries to achieve not only partial but full real convergence, which will strengthen the prospects for a successful participation into the Eurozone

\subsection{Common trends}

In this section we analyze the common stochastic trends, in order to see which countries, if any, contribute significantly to them. This is potentially useful information for the design and adjustment of policies within each country and the EU. In all cases, we tested the null hypothesis $H_{0}: \alpha_{\perp}=0$, for each country. A significant $\alpha_{\perp}$ implies that the variable of the respective country is weakly exogenous and dominates the common trend in the cointegrating system (see Hafer, Kutan and Zhou, 1997). Tables 5, 6 and 7 report the $L$-statistics for $\alpha_{\perp}$ 's for the group of the 10 enlargement countries, for the 10 enlargement countries and the 3 EMU countries and for the enlargement core and the 3 EMU countries, respectively.

Table 5 reports the results for each of the 10 enlargement countries. In the case of nominal exchange rates, Hungary's $\alpha_{\perp}$ is statistical significant, 
which means that its nominal exchange rate is weakly exogenous and contributes significantly to the five common trends of the system of nominal exchange rates. In the case of real exchange rates, the six common trends are dominated by Cyprus and the Czech Republic, while in the case of inflation, the single common trend is dominated by Hungary, Malta and the Czech Republic. All of the countries, excluding Malta, dominate the two common trends in the case of long term interest rates. For the deficit/GDP and debt/GDP ratios, the four and two common trends respectively, are dominated by Cyprus, Poland and the Slovak Republic in the former case, while they are dominated only by Lithuania in the latter case. Finally, in the case of real per capita GDP, most of the countries contribute to the four common trends. Only for Cyprus and the Slovak Republic, real per capita GDP is endogenous, which means that is affected by domestic policy actions.

Weak exogeneity in some of these variables implies that their changes reflect the impact of changes in the fundamental factors that determine their long run behavior, instead of the effects that are associated with domestic policy actions in the short run. For example, weak exogeneity in the case of interest rates reflects a similar long run behavior of all the new countries (except Malta), which is not affected by short run changes in policy. Having only two common trends in the 10 interest rates means that there is almost full convergence of interest rates policies in these countries, and they are almost ready to satisfy the Maastricht criterion of long term interest rates.

All of the above tests concern the significance of single estimates of $\alpha_{\perp}$. It is also useful to investigate which group of countries dominates each common trend. This joint test is important especially in the case of interest rates, since the cointegration process indicates almost full convergence with only two common trends. In this case, we tested if the policies of the 5 enlargement countries with high income (Cyprus, Slovenia, the Czech Republic, Hungary and Malta) jointly drive the single common trend, while the policies of the 5 enlargement countries with low income (Poland, the Slovak Republic and the three Baltic states) jointly determine the other common trend. Here the null hypothesis is $H_{0}: \alpha_{\perp}^{i}=0, i=1, \ldots, 5$ where $i$ denotes the country in each of the groups. This hypothesis implies that the specific group does not drive the common trend. In this case, the two $G$ matrices 
required to construct the $L$-statistic in equation (10) take the form:

$$
G_{\text {high income }}=\left[\begin{array}{ccccc}
1 & 0 & 0 & 0 & 0 \\
0 & 1 & 0 & 0 & 0 \\
0 & 0 & 0 & 0 & 0 \\
0 & 0 & 1 & 0 & 0 \\
0 & 0 & 0 & 0 & 0 \\
0 & 0 & 0 & 0 & 0 \\
0 & 0 & 0 & 1 & 0 \\
0 & 0 & 0 & 0 & 0 \\
0 & 0 & 0 & 0 & 0 \\
0 & 0 & 0 & 0 & 1
\end{array}\right] \text { and } G_{\text {low income }}=\left[\begin{array}{ccccc}
0 & 0 & 0 & 0 & 0 \\
0 & 0 & 0 & 0 & 0 \\
1 & 0 & 0 & 0 & 0 \\
0 & 0 & 0 & 0 & 0 \\
0 & 1 & 0 & 0 & 0 \\
0 & 0 & 1 & 0 & 0 \\
0 & 0 & 0 & 0 & 0 \\
0 & 0 & 0 & 1 & 0 \\
0 & 0 & 0 & 0 & 1 \\
0 & 0 & 0 & 0 & 0
\end{array}\right]
$$

The $L$-statistic is 123.08 in the former case and 151.43 in the latter case. The critical value of $\chi_{(10)}^{2}$ at the $5 \%$ level of significance, is 18.3. Consequently, in both cases the null hypothesis is rejected.

Table 6 shows the common trends results for the combined system of the 10 enlargement countries and the 3 EMU countries. In the case of real exchange rates, the eight common trends are dominated by Cyprus, the Czech Republic and by the 3 Eurozone countries. Hungary and the Czech Republic dominate the two common trends that exist in the system of inflation rates. Germany, France and seven new countries dominate the two common trends, in the case of interest rates. The 3 Eurozone countries dominate the four common trends, in the case of deficit/GDP ratio, while in the case of debt/GDP ratio, the three common trends are dominated by Germany and Cyprus. Finally, Latvia, Lithuania and the Netherlands dominate the five common trends, in the case of real per capita GDP.

In summary, for seven of the 10 enlargement countries and the 3 EMU countries, their long term interest rates are not affected by past disequilibria. For the rest of the variables, the 3 Eurozone countries or some of them are found to be weakly exogenous.

We expect that in the case of interest rates, Germany and France jointly drive the one of the two common trends, while the 10 enlargement countries jointly dominate the other. The reason is that Germany and France are already members of the Eurozone, while the new countries are still adjusting their policies in order to join the EMU in the near future. To test this claim 
using the $L$-statistic in equation (10), we constructed the two $G$ matrices:

$$
G_{E M U}=\left[\begin{array}{cc}
0 & 0 \\
0 & 0 \\
0 & 0 \\
1 & 0 \\
0 & 1 \\
0 & 0 \\
0 & 0 \\
0 & 0 \\
0 & 0 \\
0 & 0 \\
0 & 0 \\
0 & 0
\end{array}\right] \quad \text { and } \quad G_{n e w}=\left[\begin{array}{cccccccccc}
1 & 0 & 0 & 0 & 0 & 0 & 0 & 0 & 0 & 0 \\
0 & 1 & 0 & 0 & 0 & 0 & 0 & 0 & 0 & 0 \\
0 & 0 & 1 & 0 & 0 & 0 & 0 & 0 & 0 & 0 \\
0 & 0 & 0 & 0 & 0 & 0 & 0 & 0 & 0 & 0 \\
0 & 0 & 0 & 0 & 0 & 0 & 0 & 0 & 0 & 0 \\
0 & 0 & 0 & 1 & 0 & 0 & 0 & 0 & 0 & 0 \\
0 & 0 & 0 & 0 & 1 & 0 & 0 & 0 & 0 & 0 \\
0 & 0 & 0 & 0 & 0 & 1 & 0 & 0 & 0 & 0 \\
0 & 0 & 0 & 0 & 0 & 0 & 1 & 0 & 0 & 0 \\
0 & 0 & 0 & 0 & 0 & 0 & 0 & 1 & 0 & 0 \\
0 & 0 & 0 & 0 & 0 & 0 & 0 & 0 & 1 & 0 \\
0 & 0 & 0 & 0 & 0 & 0 & 0 & 0 & 0 & 1
\end{array}\right]
$$

respectively. In the former case, the $L$-statistic was 65.73 and $\chi_{(0.05,20)}^{2}=$ 31.4 , while in the latter case, it was 185.26 and $\chi_{(0.05,4)}^{2}=9.49$. Hence, in both cases, the null hypothesis is rejected.

Table 7 reports the results for the combined system of the 5 countries of the enlargement core and the 3 EMU countries. In the case of real exchange rates, the results show unexpectedly that the 3 Eurozone countries are not dominating any of the six the common trends. In the case of interest rates, the 3 EMU countries and Cyprus are dominating the two common trends. The 3 Eurozone countries and Cyprus dominate the two common trends in the case of deficit/GDP ratio, while in the case of debt/GDP ratio, the three common trends are dominated by Germany and Cyprus. Finally, the two common trends that exist in the case of real per capita GDP are dominated by the Netherlands, Cyprus and Slovenia. In other words, the real output of these countries is mainly affected by long run fundamental changes and international economic environment, and not by short run economic fluctuations. The weakly exogeneity of most of the nominal variables of the 3 EMU countries and Cyprus is an expected result, since Germany, France and the Netherlands are members of the Eurozone and Cyprus already satisfies most of the nominal Maastricht criteria. Also Cyprus's real per capita output is greater than the rest of the enlargement countries and closer to the EU average.

Having found only two common trends in the case of interest rates, we expect one to be driven by the 3 Eurozone countries and the other by the 
enlargement core. To test this claim, the two $G$ matrices take the form:

$$
G_{E M U}=\left[\begin{array}{ccc}
0 & 0 & 0 \\
0 & 0 & 0 \\
1 & 0 & 0 \\
0 & 1 & 0 \\
0 & 0 & 0 \\
0 & 0 & 0 \\
0 & 0 & 1 \\
0 & 0 & 0
\end{array}\right] \text { and } G_{\text {core }}=\left[\begin{array}{ccccc}
1 & 0 & 0 & 0 & 0 \\
0 & 1 & 0 & 0 & 0 \\
0 & 0 & 0 & 0 & 0 \\
0 & 0 & 0 & 0 & 0 \\
0 & 0 & 1 & 0 & 0 \\
0 & 0 & 0 & 1 & 0 \\
0 & 0 & 0 & 0 & 0 \\
0 & 0 & 0 & 0 & 1
\end{array}\right]
$$

respectively. In the former case, the $L$-statistic was 34.57 and $\chi_{(0.05,10)}^{2}=$ 18.3 , while in the latter case, it was 15.87 and $\chi_{(0.05,6)}^{2}=12.6$. Thus, in both cases, the null hypothesis is rejected.

\section{Concluding remarks}

In this study, we have presented cointegration and common trends analysis among the 10 new countries of the EU enlargement alone, as well as in relation to 3 EMU countries. Cointegration is a necessary condition for comovement of key variables in the long run and, thus for a successful future accession of the prospective new countries into the EMU. The analysis was based on the nominal convergence Maastricht criteria and an aspect of real convergence, using as a proxy the real per capita GDP's of those countries.

Our empirical results support the view that the new countries are only partially ready to join the EMU at the present. Additional work is required in order to achieve not only nominal convergence, but also real convergence among them, as well as in relation to the Eurozone countries. In order to carry out the analysis we decomposed each system of variables into its transitory and common trend components so as to identify which country or group of countries drive these trends.

More specifically, in the cases of nominal exchange rates, real exchange rates and deficit/GDP, our analysis indicates only partial convergence among these countries. In the cases of debt/GDP ratio and long-term interest rates, these countries have achieved almost full convergence among them. In the case of inflation, the results indicate full convergence among the 10 new countries. The group of the 5 enlargement countries with high income dominates the one common trend of that system, while the group of the 5 enlargement countries with low income dominates the other. The empirical findings are similar when we combine these countries with the 3 Eurozone countries. We find only partial convergence in most of the variables and almost full convergence in the cases of inflation and interest rates. In this case, the one common trend is dominated by the EMU countries and the other by the enlargement countries. Comparing the group of the richest new 
countries with the 3 EMU countries, we find almost full nominal convergence in the cases of deficit/GDP ratio and interest rates. Further we claim for almost full convergence between these two groups of countries, in terms of real output.

Overall, for all the variables specified by the Maastricht criteria, except for inflation in the system of the 10 enlargement countries, the number of common stochastic trends is greater than one. These results emphasize the need for greater coordination in monetary and fiscal policies of the enlargement countries, if they want to join the EMU in the near future. 


\section{References}

[1] Bayoumi, T. and Taylor, M.P., 1995. Macroeconomic shocks, the ERM and tripolarity. Review of Economics and Statistics, 77, 321-331.

[2] Engle, R.F. and Granger, C.W.J., 1987. Cointegration and error correction: representation, estimation and testing. Econometrica, 55, 251-276.

[3] Gonzalo, J. and Granger, C.W.J., 1995. Estimation of common longmemory components in cointegrated systems. Journal of Business and Economic Statistics, 13, 27-35.

[4] Hafer, R.W. and Kutan, A.M., 1994. A long run view of German dominance and the degree of policy convergence in the EMS. Economic Inquiry, 32, 684-695.

[5] Hafer, R.W., Kutan, A.M. and Zhou, S., 1997. Linkages in the EMS term structures: evidence from common trend and transitory components. Journal of International Money and Finance, 16, 595-607.

[6] Haug, A.A., MacKinnon, J.G. and Michelis, L., 2000. European Monetary Union: a cointegration analysis. Journal of International Money and Finance, 19, 419-432.

[7] International Monetary Fund, 2003. International Financial Statistics (IFS) CD-ROM, February, International Monetary Fund, Washington DC.

[8] Johansen, S., 1988. Statistical analysis of cointegration vectors. Journal of Economic Dynamics and Control, 12, 231-254.

[9] Johansen, S., 1991. Estimation and hypothesis testing of cointegration in Gaussian vector autoregressive models. Econometrica 59, 1551-1580.

[10] Johansen, S., 1994. The role of the constant and linear terms in cointegration analysis of nonstationary variables. Econometric Reviews, 13, 205-229.

[11] Johansen, S., 1995. Likelihood-based inference in cointegrated vector autoregressive models. Oxford University Press, Oxford.

[12] Johansen, S. and Juselius, K., (1990). Maximum likelihood estimation and inference on cointegration with applications to the demand for money. Oxford Bulletin of Economics and Statistics, 52, 169-210. 
[13] Karfakis, S.J. and Moschos, D.M., 1990. Interest rates linkages within the European Monetary System: a time series analysis. Journal of money Credit and Banking, 22, 388-394.

[14] MacDonald, R. and Taylor, M.P., 1991. Exchange rates, policy convergence and the European Monetary System. Review of Economics and Statistics, 73, 553-558.

[15] MacKinnon, J.G., Haug, A.A. and Michelis, L., 1999. Numerical distribution functions of likelihood ratio tests for cointegration. Journal of Applied Econometrics, 14, 563-577.

[16] OECD, 2002. Statistical Compendium CD-ROM, Main Economic Indicators. OECD, Paris.

[17] Osterwald-Lenum, M., 1992. A note with quantiles of the asymptotic distribution of the maximum likelihood cointegration rank test statistics. Oxford Bulletin of Economics and Statistics, 54, 461-471.

[18] Pelkmans, J., 2001. European Integration: Methods and Economic Analysis. Financial Times Prentice Hall, UK. 
Table 1

Augmented Dickey - Fuller test for a unit root ${ }^{\mathrm{a}}$

\begin{tabular}{|c|c|c|c|c|}
\hline Country & $\begin{array}{l}\text { Nominal } \\
\text { ex. rates }\end{array}$ & Inflation & $\begin{array}{c}\text { Real } \\
\text { ex. rates }\end{array}$ & $\begin{array}{c}\text { Interest } \\
\text { rates }\end{array}$ \\
\hline Cyprus & -1.97 & -2.49 & 0.01 & -1.11 \\
\hline Czech Republic & -1.36 & -0.55 & -0.90 & -2.05 \\
\hline Estonia & -2.05 & $-4.55^{*}$ & $-8.32^{*}$ & -1.31 \\
\hline France & & -2.92 & -0.69 & -1.79 \\
\hline Germany & & $-4.52^{*}$ & -0.76 & -1.91 \\
\hline Hungary & 0.16 & -2.38 & 0.54 & -1.83 \\
\hline Latvia & $-5.39^{*}$ & $-3.23^{*}$ & $-4.68^{*}$ & -0.42 \\
\hline Lithuania & $-3.63^{*}$ & $-3.42^{*}$ & $-5.62^{*}$ & -0.47 \\
\hline Malta & -2.45 & -1.09 & -0.84 & -1.66 \\
\hline Netherlands & & -2.61 & -0.61 & -2.40 \\
\hline Poland & -2.02 & $-6.76^{*}$ & -1.11 & -1.05 \\
\hline Slovak Republic & -2.36 & $-3.68^{*}$ & -0.70 & -0.35 \\
\hline Slovenia & $-4.15^{*}$ & $-5.61^{*}$ & -1.40 & -2.80 \\
\hline Country & $\begin{array}{c}\text { Deficit/ } \\
\text { GDP ratio }\end{array}$ & $\begin{array}{c}\text { Debt/ } \\
\text { GDP ratio }\end{array}$ & \multicolumn{2}{|l|}{ per capita } \\
\hline Cyprus & -1.77 & -2.14 & \multicolumn{2}{|l|}{-2.15} \\
\hline $\begin{array}{l}\text { Czech Rep. } \\
\text { Estonia }\end{array}$ & -1.03 & -1.97 & \multicolumn{2}{|l|}{$-3.82^{*}$} \\
\hline France & -1.09 & -1.84 & \multicolumn{2}{|l|}{-1.90} \\
\hline Germany & -0.84 & -2.26 & \multicolumn{2}{|l|}{-2.21} \\
\hline Hungary & & $-1.42^{\mathrm{c}}$ & \multirow{2}{*}{\multicolumn{2}{|c|}{0.28}} \\
\hline Latvia & $-1.71^{b}$ & & & \\
\hline $\begin{array}{l}\text { Lithuania } \\
\text { Malta }\end{array}$ & & $1.53^{\mathrm{c}}$ & \multicolumn{2}{|l|}{-1.97} \\
\hline $\begin{array}{l}\text { Netherlands } \\
\text { Poland }\end{array}$ & $\begin{array}{l}-1.91 \\
-2.18^{b}\end{array}$ & $\begin{array}{l}-2.45 \\
-2.50\end{array}$ & \multicolumn{2}{|l|}{0.52} \\
\hline $\begin{array}{l}\text { Slovak Rep. } \\
\text { Slovenia }\end{array}$ & -2.20 & & \multicolumn{2}{|l|}{-1.23} \\
\hline \multicolumn{5}{|c|}{ 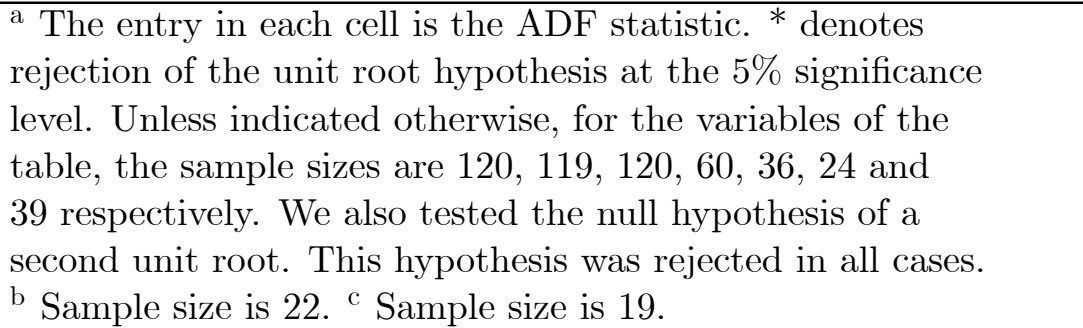 } \\
\hline
\end{tabular}


Table 2

Trace statistics: The 10 enlargement countries

\begin{tabular}{|c|c|c|c|c|c|}
\hline$(p-r)$ & $\begin{array}{l}\text { Nominal } \\
\text { ex. rates }\end{array}$ & $\begin{array}{c}\text { Deficit/ } \\
\text { GDP } \\
\text { ratio }\end{array}$ & $\begin{array}{l}\text { Debt/ } \\
\text { GDP } \\
\text { ratio }\end{array}$ & $\begin{array}{c}\text { Real } \\
\text { GDP per } \\
\text { capita }\end{array}$ & $\begin{array}{l}5 \% \text { critical } \\
\text { values for } \\
\text { Model } 1^{*}\end{array}$ \\
\hline 10 & & & & & 251.31 \\
\hline 9 & & & & & 208.41 \\
\hline 8 & & & & & 169.54 \\
\hline 7 & $174.23^{*}$ & & & & 134.70 \\
\hline 6 & $114.46^{*}$ & & & $135.81^{*}$ & 103.84 \\
\hline 5 & 76.02 & $88.41^{*}$ & $161.43^{*}$ & $80.51^{*}$ & 76.96 \\
\hline 4 & 43.05 & 41.39 & $74.84^{*}$ & 49.97 & 54.09 \\
\hline 3 & 22.01 & 14.04 & $37.53^{*}$ & 28.42 & 35.19 \\
\hline 2 & 11.97 & 7.07 & 16.93 & 13.97 & 20.25 \\
\hline 1 & 5.14 & 2.99 & 6.95 & 4.43 & 9.17 \\
\hline Lag $k$ & 1 & 1 & 1 & 1 & \\
\hline Model & $1^{*}$ & $1^{*}$ & $1^{*}$ & $1^{*}$ & \\
\hline$(p-r)$ & Inflation & $\begin{array}{c}\text { Interest } \\
\text { rates }\end{array}$ & $\begin{array}{c}5 \% \text { critical } \\
\text { values for } \\
\text { Model } 0\end{array}$ & $\begin{array}{c}\text { Real } \\
\text { ex. rates }\end{array}$ & $\begin{array}{l}5 \% \text { critical } \\
\text { values for } \\
\text { Model } 2^{*}\end{array}$ \\
\hline 10 & & $485.97^{*}$ & 219.38 & & 273.20 \\
\hline 9 & & $354.86^{*}$ & 179.48 & & 228.32 \\
\hline 8 & & $252.87^{*}$ & 143.64 & & 187.44 \\
\hline 7 & & $191.06^{*}$ & 111.79 & $158.49^{*}$ & 150.55 \\
\hline 6 & & $137.72^{*}$ & 83.94 & 105.04 & 117.69 \\
\hline 5 & & $87.69^{*}$ & 60.06 & 70.74 & 88.79 \\
\hline 4 & $132.34^{*}$ & $50.45^{*}$ & 40.17 & 43.30 & 63.87 \\
\hline 3 & $65.19^{*}$ & $27.97^{*}$ & 24.28 & 26.20 & 42.92 \\
\hline 2 & $13.24^{*}$ & 9.86 & 12.32 & 10.81 & 25.86 \\
\hline 1 & 1.56 & 0.08 & 4.13 & 4.19 & 12.52 \\
\hline $\operatorname{Lag} k$ & 1 & 3 & & 2 & \\
\hline Model & 0 & 0 & & $2^{*}$ & \\
\hline
\end{tabular}


Table 3

Trace statistics: The 10 enlargement countries and the 3

EMU countries

\begin{tabular}{|c|c|c|c|c|}
\hline$(p-r)$ & $\begin{array}{c}\text { Real } \\
\text { ex. rates }\end{array}$ & Inflation & $\begin{array}{c}\text { Deficit/ } \\
\text { GDP ratio }\end{array}$ & $\begin{array}{c}\text { Debt/ } \\
\text { GDP ratio }\end{array}$ \\
\hline 12 & & & & \\
\hline 11 & & & & \\
\hline 10 & $319.21^{*}$ & & & \\
\hline 9 & $229.49^{*}$ & & & \\
\hline 8 & 160.46 & & & \\
\hline 7 & 116.46 & & & \\
\hline 6 & 85.47 & $231.21^{*}$ & $133.84^{*}$ & $194.42^{*}$ \\
\hline 5 & 57.49 & $158.40^{*}$ & $87.76^{*}$ & $118.65^{*}$ \\
\hline 4 & 37.62 & $98.71^{*}$ & 52.84 & $71.74^{*}$ \\
\hline 3 & 20.53 & $42.77^{*}$ & 24.72 & 32.67 \\
\hline 2 & 10.60 & 12.75 & 9.79 & 13.95 \\
\hline 1 & 2.68 & 4.81 & 2.60 & 5.34 \\
\hline Lag $k$ & 2 & 1 & 1 & 1 \\
\hline Model & $1^{*}$ & $1^{*}$ & $1 *$ & $1^{*}$ \\
\hline$(p-r)$ & $\begin{array}{c}\text { Real } \\
\text { GDP per } \\
\text { capita }\end{array}$ & $\begin{array}{l}5 \% \text { critical } \\
\text { values for } \\
\text { Model } 1^{*}\end{array}$ & $\begin{array}{c}\text { Interest } \\
\text { rates }\end{array}$ & $\begin{array}{c}5 \% \text { critical } \\
\text { values for } \\
\text { Model } 0\end{array}$ \\
\hline 12 & & 348.98 & $663.13^{*}$ & 311.09 \\
\hline 11 & & 298.16 & $506.72^{*}$ & 263.25 \\
\hline 10 & & 251.31 & $364.05^{*}$ & 219.38 \\
\hline 9 & $320.09^{*}$ & 208.41 & $278.08^{*}$ & 179.48 \\
\hline 8 & $231.48^{*}$ & 169.54 & $205.48^{*}$ & 143.64 \\
\hline 7 & $157.11^{*}$ & 134.70 & $152.92^{*}$ & 111.79 \\
\hline 6 & $108.50^{*}$ & 103.84 & $112.19^{*}$ & 83.94 \\
\hline 5 & 71.59 & 76.96 & $75.00^{*}$ & 60.06 \\
\hline 4 & 45.55 & 54.09 & $46.19^{*}$ & 40.17 \\
\hline 3 & 25.16 & 35.19 & $24.96^{*}$ & 24.28 \\
\hline 2 & 12.19 & 20.25 & 9.11 & 12.32 \\
\hline 1 & 4.91 & 9.17 & 2.23 & 4.13 \\
\hline $\operatorname{Lag} k$ & 1 & & 2 & \\
\hline Model & $1^{*}$ & & 0 & \\
\hline
\end{tabular}


Table 4

Trace statistics: The enlargement core and the 3 EMU countries

\begin{tabular}{|c|c|c|c|c|c|}
\hline$(p-r)$ & $\begin{array}{c}\text { Real } \\
\text { ex. rates }\end{array}$ & $\begin{array}{c}\text { Interest } \\
\text { rates }\end{array}$ & $\begin{array}{c}\text { Debt/ } \\
\text { GDP ratio }\end{array}$ & $\begin{array}{c}\text { Real } \\
\text { GDP per } \\
\text { capita }\end{array}$ & $\begin{array}{l}5 \% \text { critical } \\
\text { values for } \\
\text { Model } 1^{*}\end{array}$ \\
\hline 8 & $222.95^{*}$ & $305.66^{*}$ & & & 169.54 \\
\hline 7 & $149.61^{*}$ & $228.87^{*}$ & & & 134.70 \\
\hline 6 & 86.89 & $167.23^{*}$ & & & 103.84 \\
\hline 5 & 56.21 & $118.78^{*}$ & $134.68^{*}$ & $114.12^{*}$ & 76.96 \\
\hline 4 & 37.24 & $73.25^{*}$ & $75.55^{*}$ & $67.38^{*}$ & 54.09 \\
\hline 3 & 20.26 & $41.87^{*}$ & 34.07 & $38.11^{*}$ & 35.19 \\
\hline 2 & 9.49 & 15.70 & 13.21 & 13.48 & 20.25 \\
\hline 1 & 2.75 & 5.28 & 4.43 & 3.03 & 9.17 \\
\hline Lag $k$ & 2 & 3 & 1 & 1 & \\
\hline Model & $1^{*}$ & $1^{*}$ & $1^{*}$ & $1^{*}$ & \\
\hline$(p-r)$ & $\begin{array}{c}\text { Deficit/ } \\
\text { GDP ratio }\end{array}$ & $\begin{array}{c}5 \% \text { critical } \\
\text { values for } \\
\text { Model } 0\end{array}$ & & & \\
\hline 8 & & 143.64 & & & \\
\hline 7 & & 111.79 & & & \\
\hline 6 & & 83.94 & & & \\
\hline 5 & $101.26^{*}$ & 60.06 & & & \\
\hline 4 & $55.55^{*}$ & 40.17 & & & \\
\hline 3 & $25.81^{*}$ & 24.28 & & & \\
\hline 2 & 5.99 & 12.32 & & & \\
\hline 1 & 1.58 & 4.13 & & & \\
\hline Lag $k$ & 1 & & & & \\
\hline Model & 0 & & & & \\
\hline
\end{tabular}

The value reported at the top of each column is for $r=0$, so that $p-r=p$, where $p$ is the number of countries included. ${ }^{*}$ denotes rejection of the null hypothesis of at most $r$ cointegrating relations, at a $5 \%$ significance level. 
Table 5

$L$-statistics: For each of the 10 enlargement countries

\begin{tabular}{cccccccc}
\hline & $\begin{array}{c}\text { Nominal } \\
\text { ex. rates }\end{array}$ & $\begin{array}{c}\text { Real } \\
\text { ex. rates }\end{array}$ & Inflation & $\begin{array}{c}\text { Interest } \\
\text { rates }\end{array}$ & $\begin{array}{c}\text { Deficit/ } \\
\text { GDP } \\
\text { ratio }\end{array}$ & $\begin{array}{c}\text { Debt/ } \\
\text { GDP } \\
\text { ratio }\end{array}$ & $\begin{array}{c}\text { Real } \\
\text { GDP per } \\
\text { capita }\end{array}$ \\
\hline Cyprus & 11.95 & $143.91^{*}$ & 2.47 & $65.13^{*}$ & $17.14^{*}$ & 1.11 & 14.32 \\
Czech Rep. & 3.09 & $15.47^{*}$ & $19.48^{*}$ & $38.42^{*}$ & 0.49 & 12.13 & \\
Estonia & 10.99 & & & $55.61^{*}$ & & & $19.79^{*}$ \\
Hungary & $23.95^{*}$ & 6.25 & $43.11^{*}$ & $37.45^{*}$ & & 4.77 & \\
Latvia & & & & $64.45^{*}$ & 6.71 & & $25.08^{*}$ \\
Lithuania & & & & $34.92^{*}$ & & $15.57^{*}$ & $21.88^{*}$ \\
Malta & 15.09 & 0.40 & $9.10^{*}$ & 20.22 & & & \\
Poland & 15.86 & 9.48 & & $37.90^{*}$ & $18.33^{*}$ & 4.89 & \\
Slovak Rep. & 6.37 & 8.80 & & $38.77^{*}$ & $22.59^{*}$ & & 11.28 \\
Slovenia & & 0.46 & & $42.14^{*}$ & & & $18.38^{*}$ \\
\hline$\chi_{(0.05)}^{2}$ & 18.3 & 12.6 & 7.81 & 26.3 & 9.49 & 12.6 & 15.5 \\
d.f. & 10 & 6 & 3 & 16 & 4 & 6 & 8 \\
\hline
\end{tabular}

${ }^{a}$ The degrees of freedom of the $\chi^{2}$-statistic equal $(p-r) \times(p-m)$, where $r$ is the number of cointegrating vectors and $m$ is the number of columns in the $G$ matrix. ${ }^{*}$ denotes rejection of the null hypothesis $H_{0}: \alpha_{\perp}=0$. 
Table 6

$L$-statistics: For each of the 10 enlargement countries and the 3 EMU countries

\begin{tabular}{|c|c|c|c|c|c|c|}
\hline Country & $\begin{array}{c}\text { Real } \\
\text { ex. rates }\end{array}$ & Inflation & $\begin{array}{c}\text { Interest } \\
\text { rates }\end{array}$ & $\begin{array}{l}\text { Deficit/ } \\
\text { GDP } \\
\text { ratio }\end{array}$ & $\begin{array}{l}\text { Debt/ } \\
\text { GDP } \\
\text { ratio }\end{array}$ & $\begin{array}{c}\text { Real } \\
\text { GDP per } \\
\text { capita }\end{array}$ \\
\hline Cyprus & $34.51^{*}$ & 3.44 & $61.58^{*}$ & 15.21 & $22.93^{*}$ & 24.38 \\
\hline Czech Rep. & $30.70^{*}$ & $20.52^{*}$ & $39.87^{*}$ & 8.70 & 4.43 & \\
\hline Estonia & & & $45.00^{*}$ & & & 13.38 \\
\hline Hungary & 17.18 & $37.27^{*}$ & $57.97^{*}$ & & & \\
\hline Latvia & & & $45.13^{*}$ & & & $32.29^{*}$ \\
\hline Lithuania & & & $34.49^{*}$ & & & $41.34^{*}$ \\
\hline Malta & 23.31 & 1.07 & 27.23 & & & \\
\hline Poland & 18.44 & & 19.77 & & 15.85 & \\
\hline Slovak Rep. & 22.69 & & $57.29^{*}$ & 10.56 & & 28.37 \\
\hline Slovenia & 10.67 & & 24.78 & & & 30.24 \\
\hline France & $33.51^{*}$ & 0.07 & $44.92^{*}$ & $23.37^{*}$ & 4.76 & 13.41 \\
\hline Germany & $32.82^{*}$ & & $42.11^{*}$ & $19.38^{*}$ & $28.27^{*}$ & 19.45 \\
\hline Netherlands & $32.46^{*}$ & 6.05 & & $21.57^{*}$ & 7.14 & $54.34^{*}$ \\
\hline$\chi_{(0.05)}^{2}$ & 26.3 & 15.5 & 31.4 & 15.5 & 16.9 & 31.4 \\
\hline d.f. ${ }^{a}$ & 16 & 8 & 20 & 8 & 9 & 20 \\
\hline
\end{tabular}


Table 7

$L$-statistics: For each of the enlargement core countries and the 3 EMU countries

\begin{tabular}{cccccc}
\hline & $\begin{array}{c}\text { Real } \\
\text { ex. rates }\end{array}$ & $\begin{array}{c}\text { Interest } \\
\text { rates }\end{array}$ & $\begin{array}{c}\text { Deficit/ } \\
\text { GDP } \\
\text { ratio }\end{array}$ & $\begin{array}{c}\text { Debt/ } \\
\text { GDP } \\
\text { ratio }\end{array}$ & $\begin{array}{c}\text { Real } \\
\text { GDP per } \\
\text { capita }\end{array}$ \\
\hline Cyprus & $30.28^{*}$ & $28.86^{*}$ & $22.81^{*}$ & $14.82^{*}$ & $16.93^{*}$ \\
Czech Rep. & $31.66^{*}$ & 14.24 & 9.91 & 6.10 & \\
Hungary & 12.76 & 18.36 & & & \\
Malta & 19.90 & 5.33 & & & \\
Slovenia & 8.55 & 19.39 & & & $36.23^{*}$ \\
France & 13.27 & $29.63^{*}$ & $17.22^{*}$ & 0.75 & 7.69 \\
Germany & 12.73 & $33.93^{*}$ & $19.40^{*}$ & $15.26^{*}$ & 9.75 \\
Netherlands & 13.47 & $29.98^{*}$ & $23.15^{*}$ & 7.54 & $15.48^{*}$ \\
\hline$\chi_{(0.05)}^{2}$ & 21.0 & 21.0 & 12.6 & 12.6 & 12.6 \\
d.f. & 12 & 12 & 6 & 6 & 6 \\
\hline
\end{tabular}

${ }^{a}$ The degrees of freedom of the $\chi^{2}$-statistic equal $(p-r) \times(p-m)$, where $r$ is the number of cointegrating vectors and $m$ is the number of columns in the $G$ matrix.

* denotes rejection of the null hypothesis $H_{0}: \alpha_{\perp}=0$. 